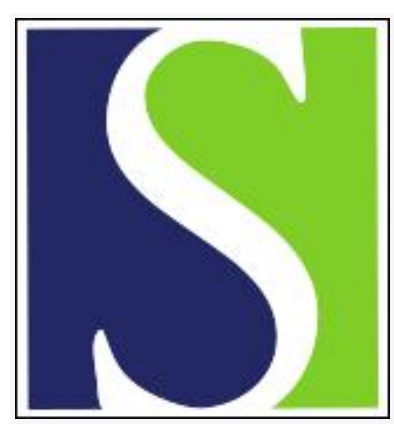

Scand J Work Environ Health 1990;16(4):294

https://doi.org/10.5271/sjweh.1781

Issue date: 01 Aug 1990

Health and safety requirements of jobs.

by Chaplin J, Edwards F, Floyd M

This article in PubMed: www.ncbi.nlm.nih.gov/pubmed/2389138

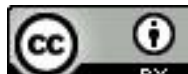

This work is licensed under a Creative Commons Attribution 4.0 International License 


\section{Health and safety requirements of jobs}

We are undertaking a study of the systems used by occupational physicians and others to categorize jobs when placing an individual with a disability or health problem in a job. This study is being funded by a grant from the Health and Safety Executive in Great Britain and will continue into 1991 .

Occupational physicians, when faced with an employee who has unsatisfactory work performance or lengthy sickness absence due to a medical condition, must judge whether that employee should be retained in his or her present employment, moved to another job, or released from employment.

Recent research has suggested that it can be extremely difficult to arrive at a decision which balances the individual's rights and abilities against the need to meet the health and safety requirements of the work and the employer's expectations of adequate work performance.

To provide the best possible advice, the occupational physician requires detailed knowledge not only of the medical condition, but also of the work environment and the special requirements of jobs within that environment.
This study will attempt to evaluate present methodologies and their use and to determine whether a systematic and standardized system of job analysis can be developed which is both relevant to the work of occupational physicians and practicable for them to use.

We would greatly appreciate hearing from anyone who has had experience using different methods of job analysis or classifications of health and safety requirements of jobs or tasks. We would also welcome suggestions on what type of information would be of the most use to the occupational physician.

If anyone wishes to write, please contact John Chaplin at the address below.

John Chaplin, MSc, Felicity Edwards, MD, Mike Floyd, $\mathrm{PhD}$

Rehabilitation Resource Centre

Systems Science Department

The City University

Northampton Square

London EC1V OHB

England 